\title{
The Solar and Magnetic Conditions Associated with Recent Auroras
}

\author{
By the Rev. J. P. Rowland, S.J.
}

\begin{abstract}
$\mathrm{A}^{\mathrm{S}}$
S already noted in Nature (Feb. 13, 20 and 27), notable displays of the aurora were observed on January 7 and February 3, and it was anticipated there might be a recurrence after the 27-day interval of solar rotation on March 2. Weather was generally cloudy or overcast and unfavourable for observation on the last-mentioned date, but Mr. W. N. Craig, of Fortrose, Ross-shire, writes that an observer near Cambridge reported seeing the aurora between $20 \mathrm{~h}$. and $21 \mathrm{~h}$., with a maximum brightness at $20 \mathrm{~h} .45 \mathrm{~m}$. U.T., and another observer at South Queensferry, near Edinburgh, in a small clearing at $19 \mathrm{~h} .45 \mathrm{~m}$., noted the sky to be brighter than usual. Two persons near Stonyhurst, in a brief partial clearing of the sky, reported seeing auroral rays between $20 \mathrm{~h} .20 \mathrm{~m}$. and $20 \mathrm{~h} .30 \mathrm{~m}$., and an observer in the vicinity of Preston noted indications of aurora with rays, between $23 \mathrm{~h}$.
\end{abstract}

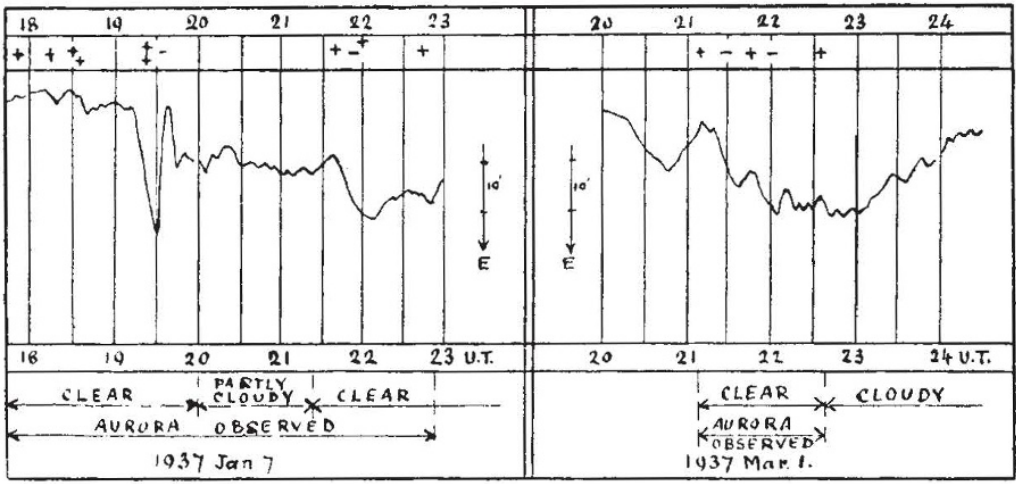

As Mr. Housman points out, it appears that in general the arch forms during an easterly swing of the magnet, and dissolves into an outburst of streamers and other luminous effects at or near the end of the easterly swing. It also appears from these observations, that auroral features may be seen when there is very little disturbance of the magnets, though a greater disturbance accompanies a more vivid display, as on February 3 .

Mr. Craig mentions an aurora seen in Maine, U.S.A., "in the middle of December", but as no date is given, it is not possible to correlate this with the magnetic conditions, which were, in fact, remarkably quiet throughout the month, with the exception of a moderate disturbance on December 27 and 28. The auroral display of October 16, 1936, discussed by Prof. Vegard in Nature of November 28 (p. 930), was accompanied by a very notable magnetic disturbance, lasting from October 16d. 15h. to 17d. 7h., with oscillations in declination of $28^{\prime}$ between $18 \mathrm{~h}$. and $20 \mathrm{~h}$., a rapid easterly deflection of $23^{\prime}$ at $22 \mathrm{~h}$. $30 \mathrm{~m}$., and a range of $39^{\prime}$ over the whole disturbance.

When we come to consider the relation of these phenomena to solar activity, we are on less sure ground. According to generally accepted theory, both auroras and magnetic disturbances are attributable to the emission of streams of corpuscles from disturbed areas on the sun, which travelling with high velocity under the action of and 23h. 25m. On the other hand, Mr. W. B. Housman, director of the Aurora Section of the British Astronomical Association, observing over the Solway Firth from Seaton, Cumberland, reports : "On March 2nd there was no aurora seen throughout a cloudless night here, observations being at very frequent intervals". On the Stonyhurst magnetic traces there was a moderate magnetic disturbance from $18 \mathrm{~h} .40 \mathrm{~m}$. to $19 \mathrm{~h} .40 \mathrm{~m}$, after which conditions were quiet, with only very slight movements.

On March 1, however, a prolonged and bright quiescent aurora was observed at Stonyhurst, from $20 \mathrm{~h}$. $45 \mathrm{~m}$. to $23 \mathrm{~h}$. $30 \mathrm{~m}$., which was especially bright between $21 \mathrm{~h}$. $30 \mathrm{~m}$. and $23 \mathrm{~h}$., extending to an altitude of $35^{\circ}$ or $40^{\circ}$, gradually fading away to a slight glow by $23 \mathrm{~h}$. $30 \mathrm{~m}$. when observation ended. This aurora, and that of January 7 , were observed in great detail by Mr. Housman at Seaton, and from a correlation of his log with the Stonyhurst magnetic declination traces, some interesting inferences may be drawn. This correlation, as made by Mr. Housman, is shown in the diagram above; the signs + and - above the declination trace, indicate respectively when a homogeneous arch was in being at the time indicated, and when the arch dissolved into streamers and luminous activity. The sign $\ddagger$ indicates the existence of a double arch, during the large easterly deflection of the magnet between 19h. $15 \mathrm{~m}$. and $19 \mathrm{~h} .30 \mathrm{~m}$, on January 7 . radiation pressure enter the earth's upper atmosphere, and there set up ionization currents and electrical discharges in the rarefied gases, which manifest themselves in the disturbance of the earth's magnetic field, and the glows of the auroral light. The frequency of both auroras and magnetic storms, and the mean annual magnetic ranges, show a close correla. tion with the 11-year sunspot cycle, and both show a recurrence tendency after 27-day intervals, corresponding to the mean solar rotation period.

When we come, however, to the consideration of individual correspondences, the position is not so clear. There are cases where large sunspots cross the disk without any obviously corresponding mag. netic disturbance, and conversely, magnetic disturbances occur when there are no spots on the sun. It should be remembered that sunspots are not the only manifestation of solar activity, and magnetic disturbances may be associated with the presence of faculæ, bright or dark flocculi, and eruptions on the disk, which, at the limb, would be seen as prominences. In the case of magnetic disturbances which are apparently associated with individual spots, statistical investigations show that the magnetic disturbance may occur from 1-2 days before to 3-4 days after the central meridian passage of the spot, corresponding to mean corpuscular velocities of $1,100-270$ miles per second.

There is good ground for believing that the recent 
auroras and accompanying magnetic disturbances were due to the activity of a region of the sun centred in approximately lat. $10^{\circ} \mathrm{S}$., long. $200^{\circ}$. In this area, the centre of an enormous spot group, extending over $8^{\circ}$ in latitude and $16^{\circ}$ in longitude, crossed the sun's central meridian within $4^{\circ}$ of the centre of the disk at approximately midnight of January 30-31. It was therefore in a most effective position for a roughly radial stream of corpuscles to be intercepted by the earth, and the magnetic disturbance and surora of February 3 must be attributed to it. The same region crossed the central meridian on January 3 and February 26, in each case showing a spot of moderate size, the times of central meridian passage being Jan. 3d. 9h. and Feb. 26d. 18h. respectively, and it is reasonable to suppose that the phenomena of January 7 and March 2 were associated with this area. The aurora and magnetic disturbance of March 1 were probably not associated with this area, but with a small group of spots in lat. $11^{\circ} \mathrm{S}$., long. $228^{\circ}$, which crossed the central meridian on Feb. 25d. $0 \mathrm{~h}$. If these inferences are correct, the time intervals between the central meridian passages of the spots and the respective auroras, and the deduced corpuscular velocities are as follows :

$\begin{array}{ccc}\text { Date of Aurora. } & \text { Time Interval. } & \text { Corpuscular Velocity. } \\ \text { Jan. } 7 . & \text { 4d. 10h. } & 250 \text { miles per sec. } \\ \text { Feb. 3. } & \text { 4d. 19h. } & 220, ", ", \\ \text { Mar. 1. } & \text { 4d. 22h. } & 217, ", ", \\ \text { Mar. 2. } & \text { 4d. 0h. } & 280, ", ",\end{array}$

On February 25 there was an extensive belt of spot groups stretching almost across the disk in the northern hemisphere of the sun, but as there was no corresponding sustained magnetic disturbance, these groups appear to have been magnetically comparatively inactive, probably on account of their distance from the centre of the disk, which averaged about $20^{\circ}$. A large naked-eye spot in lat. $9^{\circ} \mathrm{N}$. crossed the central meridian on March $2 \mathrm{~d}$. $0 \mathrm{~h}$., but it is unlikely that this was associated with the aurora on that day or the previous one, both on account of the lack of the requisite time interval, and because, owing to the backward tilt of the sun's axis, it was $16^{\circ}$ from the centre of the disk, where it would be less effective. It may, however, have been responsible for a moderate magnetic disturbance on March 5.

Mr. Craig suggests that the aurora of October 16, 1936, may belong to the same series as the recent displays, but this seems unlikely, as it would involve a mean interval of $27 \cdot 5$ days, corresponding to the solar rotation period in latitude $20^{\circ}$, whereas the spots involved in the recent cases had a latitude of $10^{\circ}$, with a rotation period of 27.05 days. A spot of appreciable size in lat. $12^{\circ} \mathrm{S}$., long. $225^{\circ}$ crossed the central meridian on October $11 \cdot 8$, and may have been responsible for the aurora and magnetic storm of October 16. As this position is very nearly the same as that of the group which has been suggested above as probably responsible for the display of March 1, it would appear that these two occurrences may be considered as belonging to a separate series different from that of the displays of January 7 , February 3 and March 2. This case, however, illustrates the difficulty of assigning individual correspondence between solar and terrestrial phenomena, for on October 12 a sporadic group of small spots crossed the central meridian in lat. $18^{\circ} \mathrm{N}$., which, owing to the forward tilt of the sun's axis at that time, was only $12^{\circ}$ from the centre of the disk, and therefore in a more favourable position to produce terrestrial effects than the southern spot, the distance of which from the centre was $18^{\circ}$.

With the approach to the time of sunspot maximum, conditions for the production of tne aurora are likely to be frequent during the next two years, but owing to the decreasing hours of darkness, conditions for observing the displays will not be favourable until next autumn or winter, when it is to be expected many displays may be seen.

\section{The Development Commission}

$\mathrm{T}$ HE twenty-sixth report* of the Development Commissioners, covering the year ended March 3], 1936, reviews the expenditure from the Development Fund on agricultural and rural economy, fisheries, the construction and improvement of harbours and on the acquisition of land for road improvements. Advances recommended from the Fund amounted to $£ 555,201$ on agricultural and rural industries and $£ 85,925$ on fisheries as against $£ 402,859$ and $£ 88,109$, respectively, in 1934-35. For the maintenance of agricultural research, advisory services for farmers, experiments on field crops and livestock and the provision of buildings and equipment $£ 421,762$ was advanced as against $£ 361,691$ in 1934-35. Of this, £285,984 was advanced to the Ministry of Agriculture and Fisheries, $£ 67,101$ to the Department of Agriculture of Scotland and $£ 16,982$ to the Agricultural Research Council, in addition to $£ 43,000$ to the latter Council for capital expenditure.

* Development Commission. Twenty-sixth Report of the Development Commissioners, being for the Year ended the 31st March 1936. Pp. 184. (London: H.M. Stationery Office, 1937.) 38. net.
The advances to the two Agricultural Departments include $£ 198,170$ for maintenance grants to Research Institutes in England and Wales and $£ 40,966$ for those in Scotland. The total provision recommended during the year for research and advisory activities in agriculture in Great Britain amounted to $£ 369,977$, a generous figure in comparison with State assistance to other industries, although even at this figure research expenditure only amounts to about 0.14 per cent of the value of the year's output.

For the first time since 1931 a considerable sum was approved for the erection of new buildings at institutions engaged in research or agricultural education. Grants have been approved for this purpose to the Studley College for Women, the Royal Agricultural College, Cirencester, the University College of North Wales, Bangor, the Midland Agricultural College, the Avoncroft Agricultural College, and the Royal (Dick) Veterinary College, Edinburgh. Assistance given to rural industries has three principal aims : the provision of technical advice for craftsmen by the Rural Industries Bureaux; the interest of 